\title{
ANÁLISE DE INDICADORES DE DESENVOLVIMENTO DA REGIÃO CENTRO-OESTE DO BRASIL ${ }^{1}$
}

\author{
Ricardo Fernandes SANTOS ${ }^{2}$ \\ Madalena Maria SCHLINDWEIN ${ }^{3}$
}

${ }^{2}$ Bacharel em Administração UFGD - rfc.rfc.ricardo@ gmail.com

${ }^{3}$ Doutora em Economia Esalq/USP. Professora e Pesquisadora UFGD - madalenaschlindwein@ufgd.edu.br

\section{Recebido em: 30/05/2014 - Aprovado em: 30/06/2014 - Disponibilizado em: 30/07/2014}

RESUMO: O objetivo central deste artigo é fazer uma análise do nível de desenvolvimento socioeconômico da região Centro-Oeste do Brasil. Os dados utilizados são oriundos do IBGE (Instituto Brasileiro de Geografia e Estatística), Banco Central do Brasil, de sites e livros. Para esta análise foram considerados dados como: Índice de Desenvolvimento Humano, taxa de alfabetização, PIB (Produto Interno Bruto) per capita, acesso à serviços básicos como saneamento e comunicações, renda média etc. Os resultados apontam que o nível de desenvolvimento da região Centro-Oeste destacase no cenário nacional, porém ainda persistem problemas socioeconômicos, não apenas na região como também no Brasil, que impedem uma melhor performance de seu desenvolvimento.

Palavras-Chave: Análise. Economia Regional. Centro-Oeste. Indicadores. Desenvolvimento.

\section{ANALYSIS OF INDICATORS OF DEVELOPMENT OF THE BRAZILIAN MIDWEST REGION}

\begin{abstract}
The goal of this paper is make an analysis of the socioeconomic development level of the Brazil Midwest region. Data used are from IBGE (Instituto Brasileiro de Geografia e Estatística), Brazil Central Bank, sites and books. For this analysis were used data like: Human Development Index, literacy rate, GDP (Gross Domestic Product) per capita, access to basic services as sanitation and communication, average income etc. The results show the Midwest development level stands in national scene, but there are still socioeconomic problems, in brazilian Mid-West region and in Brazil too, impeding a better performance of its development.
\end{abstract}

Key Words: Analysis. Regional Economy. Midwest Region. Indexes. Development.

1 Este artigo é parte dos resultados de Projetos de Pesquisa financiados pelo CNPq. 


\section{INTRODUÇÃO}

Este artigo tem como objetivo fazer uma caracterização socioeconômica da região Centro-Oeste do Brasil. A partir disso pretende-se analisar o perfil de desenvolvimento socioeconômico da região.

Alguns autores buscam diferenciar desenvolvimento de crescimento econômico. Para Furtado (1986) o crescimento econômico se relaciona apenas com o aumento da produção real, não modificando as funções de produção, é expressado por índice de volume físico da produção. Desenvolvimento econômico se relaciona com crescimento econômico, porém representa muito mais que um simples crescimento, alterando uma estrutura mais complexa, as formas sociais e econômicas de divisão do trabalho social, satisfazendo as necessidades coletivas. Para o autor, a hipótese de crescimento não acompanhado de desenvolvimento, seria sem sentido, na realidade. Assim, para compreender o desenvolvimento, é preciso conhecer os agentes decisivos e os fatores estruturais que propagam os efeitos das decisões.

Também Schumpeter (1985) busca diferenciar os termos crescimento e desenvolvimento econômico. Para ele crescimento econômico não é designado desenvolvimento econômico, pois o crescimento não apresenta nada qualitativamente novo, apenas é um processo de adaptação e alterações de dados.
Segundo
Furtado
(1986),

desenvolvimento se refere a mudanças na vida econômica que emergem internamente, por autoiniciativa. Se não há mudanças na vida econômica por iniciativa própria e se apenas a economia se adapta aos novos dados, então não há desenvolvimento econômico.

Para Souza (2005), os indicadores de desenvolvimento podem ser sintetizados no Índice de Desenvolvimento Humano (IDH), elaborado pelo PNUD (Programa das Nações Unidas para o Desenvolvimento). Esse índice mede o nível de desenvolvimento de regiões, sejam países, estados, cidades, etc.

Os investimentos privados e públicos no Centro-Oeste permitiram à região uma transformação socioeconômica e levam ao desenvolvimento tanto da agricultura quanto da pecuária, atividades que representam a base econômica da região, além de ter ampliado muito sua infra-estrutura (GUIMARÃES; LEME, 1997).

$\mathrm{Na}$ década de 1930 houve profundas mudanças na forma de atuação do estado e de expansão do mercado interno refletindo diretamente no Centro-Oeste. O programa Marcha Para o Oeste do governo de Getúlio Vargas previa a colonização das fronteiras e povoamento de regiões com baixa densidade demográfica (PAVÃO, 2005). O impacto da Marcha Para o Oeste logo foi sentido nos estados do Centro-Oeste. Com essa política, a região Centro-Oeste logo foi povoada (GUIMARÃES; LEME, 1997).

A partir de 1960 o fluxo migratório para a região Centro-Oeste diminui, porém 
torna-se mais qualificado. Os migrantes, paranaenses, gaúchos e paulistas, possuíam maior experiência no trabalho de lavoura e criação de animais (GUIMARÃES; LEME, 1997).

Os grandes investimentos na região Centro-Oeste, desde a construção de Brasília, de programas como o Marcha para o Oeste e o os investimentos do POLOCENTRO desenvolveram a infra-estrutura regional surgindo novos pólos urbanos.

A região tem como principais potencialidades os recursos naturais abundantes, capacidade empreendedora, este se refere aos colonizadores que com pouco incentivo desenvolveram a agricultura na região, agropecuária produtiva e moderna, a inovação tecnológica no campo, sobretudo com as pesquisas da Embrapa, e pela sua posição estratégica no centro da América do Sul (MINISTÉRIO DA INTEGRAÇÃO NACIONAL, 2010).

Alguns autores buscam diferenciar desenvolvimento de crescimento econômico.

Dentre as deficiências sociais e econômicas na região Centro-Oeste, destacam-se a vulnerabilidade econômica das commodities, deficiências na qualificação da mão de obra, problemas na logística e infraestrutura econômica, falta de sentimento de identidade regional, visto que a região é colonizada por pessoas de variadas localidades, desigualdade socioeconômica e desarticulação da rede urbana, assim como o déficit habitacional apresentado, com poucas cidades estruturadas (MINISTÉRIO DA INTEGRAÇÃO NACIONAL, 2010).

\section{METODOLOGIA}

O método utilizado neste estudo refere-se a uma análise exploratória e descritiva de alguns indicadores como: PIB (Produto Interno Bruto), PIB per capita, IDH (ìndice de Desenvolvimento Humano), taxa da população com acesso aos serviços básicos, taxa de analfabetismo, valores da balança comercial entre outros.

Para tanto, como fonte de dados foram utilizadas as publicações de órgão oficiais do governo, as publicações do IGBE e do Banco Central do Brasil, Ministério da Integração Nacional entre outros, além de revistas científicas e livros. Os dados foram coletados e apresentados em forma de tabelas e gráficos e, após, analisados. O período de análise concentra-se no período de 2005 a 2010.

\section{1 Área de Estudo}

A região Centro-Oeste do Brasil possui cerca de $1.606 .371 \mathrm{~km}^{2}$ de extensão, e tem a menor população se comparada com outras regiões brasileiras, 13,7 milhões de habitantes (IBGE, 2009).

\section{RESULTADOS E DISCUSSÕES}

A discussão dos resultados divide-se em 4 partes. A primeira analisa as variáveis socioeconômicas da região Centro-Oeste brasileira, a segunda trata do acesso aos serviços básicos, a terceira parte faz uma análise da balança comercial regional e, por fim, a quarta parte faz uma abordagem a cerca 
dos entraves socioeconômicos da região.

\subsection{Indicadores Socioeconômicos}

No gráfico 01 há uma comparação entre os PIBs (Produto Interno Bruto) das Unidades Federativas da região Centro-Oeste. Verifica-se que a mesma possui um PIB de R $\$$ 279,015 bilhões (2008), divididos pelos estados de Mato Grosso (R \$ 53,023 bilhões), Mato Grosso do Sul (R\$ 33,145 bilhões), Goiás (R \$ 75,275 bilhões) e o Distrito Federal (R\$ 117,572 bilhões). A região participa com 9,2\% do PIB do Brasil (R $\$ 3.031,864$ bilhões, 2007) (IBGE, 2010a).

Gráfico 01: PIB Corrente das Unidades Federativas da Região Centro-Oeste - 2008.

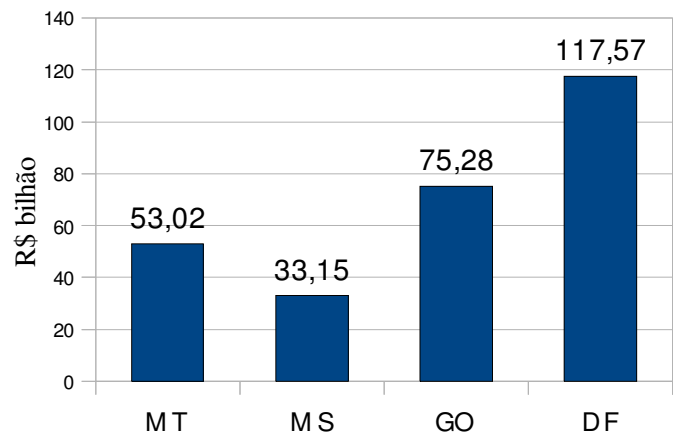

Fonte: Elaborado com base em (IBGE, 2010a).

O PIB per capita da região Centro-

Oeste é o segundo maior do país, $\mathrm{R} \$$ 20.372,10, atrás apenas do da região Sudeste, de $\mathrm{R} \$ 21.182,68$. O motivo por esse resultado é a alta taxa do PIB per capita do Distrito Federal (R\$ 45.977,59), o maior do país. Há uma grande disparidade entre o PIB per capita do Distrito Federal e o dos estados da região, Mato Grosso do Sul (R\$ 14.188,41), Mato Grosso (R\$ 17.927) e Goiás (R\$ 12.878,52). Essa diferença pode ser visualizada no Gráfico 02.

Gráfico 02: PIB per capita das Unidades Federativas da Região Centro-Oeste - 2008.

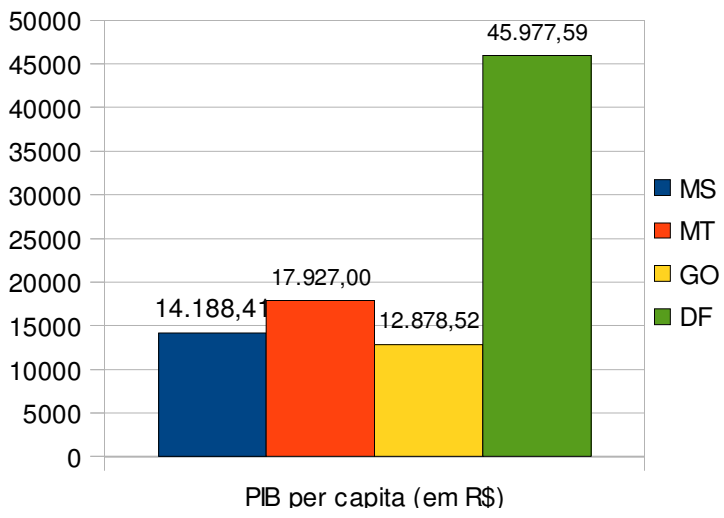

Fonte: Elaborado pelos autores com base em (IBGE, 2010a).

O IDH (Índice de Desenvolvimento Humano) da região Centro-Oeste do Brasil, pela metodologia de análise do IDH anterior a de 2010, é de 0,815 (2005) considerado elevado.

O IDH da região Centro-Oeste é elevado motivado pelo IDH do Distrito Federal (0,874 em 2005), que possui o melhor índice entre as unidades federativas do Brasil. Os estados da região apresentam índices um pouco abaixo deste valor, porém também são considerados de alto desenvolvimento; Mato Grosso (0,796), Mato Grosso do Sul $(0,802)$ e Goiás $(0,800)$ (CEPAL;PNUD;OIT, 2008).

No gráfico 03 apresenta os valores dos IDHs das Unidades Federativas do CentroOeste juntamente com os valores dos elementos de formação do respectivo índice. 
Gráfico 03: Formação do IDH - Reg. C-O - 2005

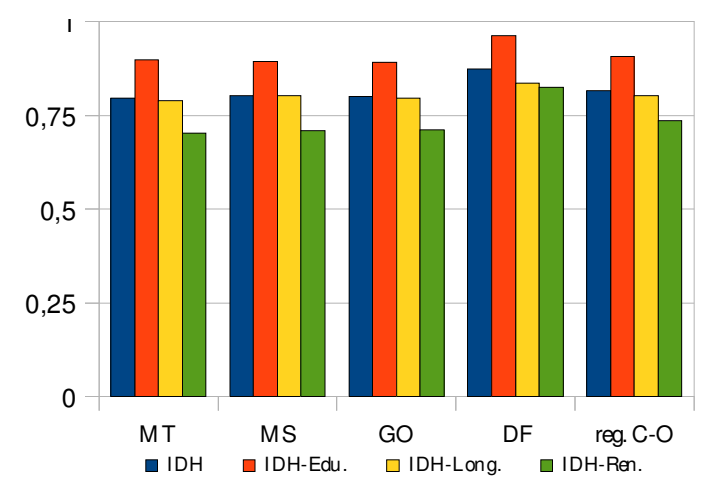

Fonte: Baseado em (CEPAL;PNUD;OIT, 2008).

Conforme o Gráfico 03, quanto à formação do IDH, a região apresenta os seguintes índices: IDH-Educação $(0,906)$, IDH-Longevidade $(0,803)$ e IDH-Renda (0,736), destaque-se a importância de indicadores de educação acima de 0,9.

Quando se compara a região CentroOeste com as demais regiões do país verificase que a mesma apresenta o terceiro maior índice, tendo a região sul o melhor $(0,829)$, seguida da região sudeste $(0,824)$, a região norte com o quarto índice $(0,764)$ e a região nordeste o menor índice da comparação (0,720) (CEPAL;PNUD;OIT, 2008).

O gráfico 04 permite observar a melhora da qualidade de vida, medida através do IDH, na região Centro-Oeste, comparando com a média nacional no mesmo período.
Gráfico 04: IDH -Brasil e Centro-Oeste - 1991, 1995, 2000 e 2005.

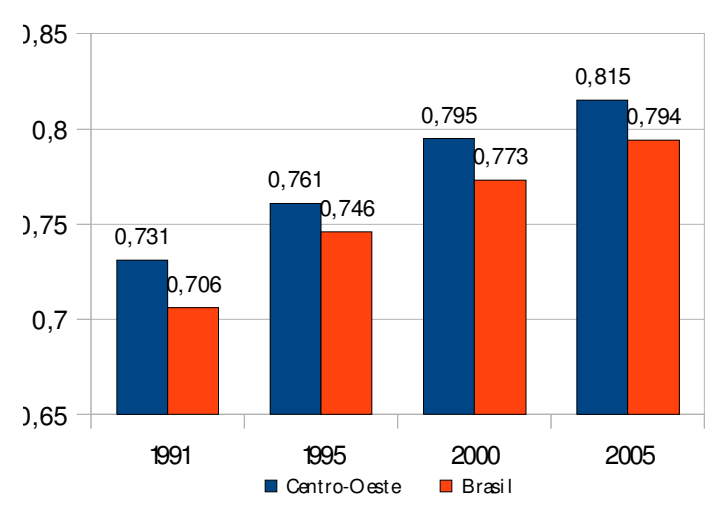

Fonte: Baseado em (CEPAL;PNUD;OIT, 2008).

Os dados apresentados acima mostram a enorme desigualdade regional existente no Brasil, assim como também na região CentroOeste principalmente no que diz respeito a renda e desenvolvimento humano.

$\mathrm{Na}$ região Centro-Oeste os índices sociais apresentam-se elevados por causa da condição mais desenvolvida do Distrito Federal, desta forma a região se destaca no país, porém isso não representa bem as condições dos estados da região.

O índice de Gini, que permite mostrar o grau de concentração de renda, da região Centro-Oeste é de 0,541 (2007) e do Brasil é de 0,540 (2007). Ambos os índices são considerados altos e revelam a enorme desigualdade social existente no país e, especificamente, na região Centro-Oeste (MATO GROSSO DO SUL, 2009).

No Centro-Oeste o rendimento por domicílio, conforme IBGE (2010b), é de R \$ 2.731,14, sendo mesmo rendimento para a média nacional de $\mathrm{R} \$ 2.641,63$. Comparando com as demais regiões brsileiras, o Centro- 
Oeste tem o terceiro melhor rendimento domiciliar do país atrás da região Sudeste, com $\mathrm{R} \$ 2.641,63, \mathrm{Sul}$, com $\mathrm{R} \$ 2.873,52$, e à frente das regiões Norte, $\mathrm{R} \$ 2.011,72$, e Nordeste, R\$1.712,88.

\subsection{Moradia e Serviços Básicos.}

A região Centro-Oeste possui 4,26 milhões de domicílios particulares tendo um número médio de ocupação por domicílio de 3,2 pessoas. O número médio de ocupação das regiões Sul e Sudeste é 3,1 pessoas por domicílio, na região Norte é de 3,8 pessoas por domicílio e na região Nordeste é de 3,6 pessoas por domicílio (IBGE, 2009).

Dos domicílios urbanos da região Centro-Oeste, 3,71 milhões, $67,8 \%$ são próprios, $23,7 \%$ alugados, $8,1 \%$ cedidos e $0,4 \%$ ocupados de outras formas. As taxas médias brasileiras de domicílios alugados (19\%) e cedidos $(6,4 \%)$ são menores que as taxas da região Centro-Oeste; e a taxa brasileira de domicílios próprios $(74,1 \%)$ é maior que mesma taxa da região (IBGE, 2009).

Dos domicílios urbanos da região Centro-Oeste $90 \%$ são casas, $9,3 \%$ apartamentos e $0,6 \%$ cômodos; porém se analisar isoladamente a taxa do Distrito Federal vê-se uma grande diferença nas taxas de domicílios casa $(72,9 \%)$, bem abaixo da média da região, e de domicílios apartamentos $(26,5 \%)$, taxa bem acima da média regional (IBGE, 2009).

No Centro-Oeste $38,9 \%$ dos domicílios possuem serviço de saneamento, dos domicílios com renda média per capita de até meio salário mínimo esta taxa é de $27,3 \%$, porém passa para $54,7 \%$ quando os domicílios tem renda média per capita acima de 5 salários mínimos.

A taxa de domicílios com acesso a serviço de abastecimento de água, na região Centro-Oeste, é de 90,5\%, restando 9,5\% dos domicílios da região sem acesso a este serviço. A taxa de domicílios urbanos com serviço de esgotamento sanitário na região é de $45,1 \%$, outros $54,1 \%$ dos domicílios usam fossa e $0,9 \%$ outras formas de esgotamento (IBGE, 2009).

Quanto ao acesso à coleta de lixo nos domicílios urbanos, esta taxa é de 98,9\%, taxa um pouco maior que a média brasileira, 98,1\% (IBGE, 2009).

O Gráfico 05 elenca o acesso a serviços básicos na região Centro-Oeste.

Gráfico 05: Acesso a serviços básicos na região Centro- Oeste - $2008(\mathrm{em} \%)$.

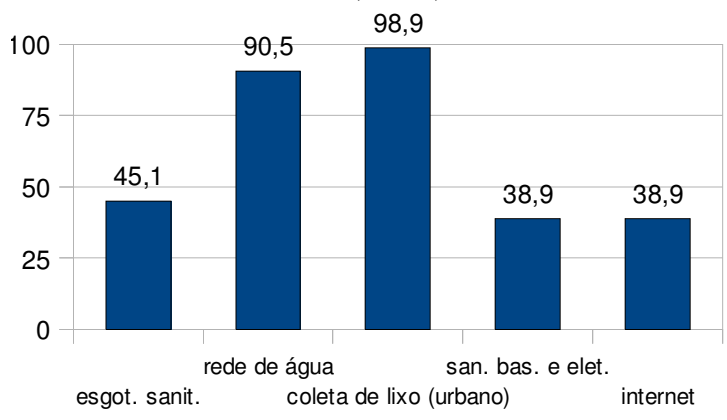

Fonte: Elaborado pelos autores com base em (IBGE, 2009).

Conforme o gráfico 05 , a taxa de acesso simultâneo aos serviços de saneamento e de eletricidade dos domicílios urbanos da região Centro-Oeste é de 38,9\%, índice muito abaixo da média nacional de $61 \%$. A taxa de 
domicílios urbanos com acesso a internet na região Centro-Oeste é de $26,4 \%$, taxa um pouco abaixo da média nacional de $27,5 \%$.

\subsection{Entraves Socioeconômicos:}

A educação é algo essencial para o desenvolvimento, assim também como diminuir as desigualdades sociais e proporcionar acesso da sociedade aos diversos serviços básicos de qualidade, tanto na perspectiva brasileira quanto na da região Centro-Oeste especificamente.

A taxa de analfabetismo, pessoas de 15 anos ou mais analfabetas, da região Centro-Oeste é de 8,2\%. Ao observar esta taxa pelo nível de renda o índice apresenta grande variação, para rendimentos familiares per capita de até meio salário mínimo a taxa chega a $12,3 \%$, enquanto que a mesma taxa para rendimentos acima de dois salários mínimos é de 2\% (IBGE, 2009).

Analisando a taxa de analfabetismo das regiões brasileiras observa-se que enquanto as regiões Sul, Sudeste e CentroOeste apresentam taxas menores que $10 \%$, respectivamente $5,5 \%, 5,8 \%$ e $8,2 \%$, as regiões Norte e Nordeste apresentam índices superiores a $10 \%$, respectivamente $10,8 \%$ e $19,4 \%$, como pode ser observado no Gráfico 06.
Gráfico 06: Taxa de Analfabetismo - regiões brasileiras (em \%).

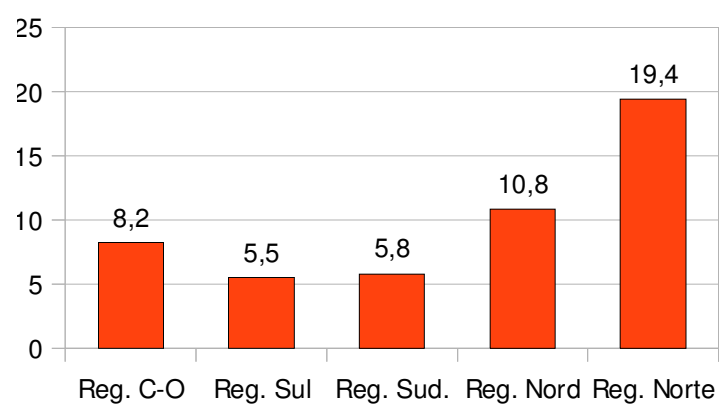

Fonte: Elaborado pelos autores com base em (IBGE, 2009).

Quanto ao Brasil, a taxa de analfabetismo é de $10 \%$, porém ao observar pelo nível de rendimento a taxa para até meio salário mínimo é de $17,5 \%$ e para mais de dois salários mínimos de 2\% (IBGE, 2009).

A taxa de analfabetismo funcional na região Centro-Oeste é de 19,2\%, e no Brasil é de $21 \%$. Ambas as taxas mostram que o problema na educação não é apenas o acesso, mas também a qualidade (IBGE, 2009).

A taxa de frequência escolar de pessoas com idade entre 7 e 14 anos no ensino fundamental na região Centro-Oeste, é de 94,5\% enquanto que no Brasil é de 94,9\%. Ao observar esta taxa por unidade federativa da região Centro-Oeste tem-se, Distrito Federal 95,9\%, Mato Grosso do Sul 95,6\%, Goiás 94,3\% e Mato Grosso 92,8\% (IBGE, 2009).

Quanto às outras regiões brasileiras, todas apresentam índices acima de 90\%, Norte $93,6 \%$, Nordeste $94,4 \%$, Sudeste $95,7 \%$ e Sul 95,2\%, assim como todos os estados apresentam também índices acima de 90\% (IBGE, 2009).

Quando se analisa a taxa de frequência 
escolar de pessoas de 15 a 17 anos no ensino médio esta é de $51,8 \%$ para a região CentroOeste e de 50,4\% para o Brasil. Numa comparação com os estados da região CentroOeste tem-se, Mato Grosso do Sul 47,5\%, Mato Grosso 50,2\%, Goiás 53,4\% e o Distrito Federal 54,9\% (IBGE, 2009).

Estes dados mostram que a evasão escolar na região Centro-Oeste está acentuada. Nos últimos anos da educação básica, até mesmo no Distrito Federal, onde há uma condição socioeconômica, há uma menor frequência de pessoas nos últimos anos da educação básica do que nas faixas iniciais. Além do acesso e da qualidade outro problema na educação é a evasão escolar (IBGE, 2009).

A taxa de pessoas, com 25 anos ou mais, que possuem 11 anos de estudo, ou seja, concluíram o ensino básico na região CentroOeste é de 21,2\%. Porém se a análise for feita para as unidades federativas da região concluí-se que a taxa do Distrito Federal $(27,5 \%)$ eleva a taxa média regional, pois os estados de Mato Grosso do Sul (18,7\%), Mato Grosso (19\%) e Goiás (20,6\%) possuem a respectiva taxa com valor inferor a média regional (IBGE, 2009).

Ao considerar mais de 15 anos de estudo, para o grupo populacional de 25 anos ou mais, a região Centro-Oeste tem uma taxa de $10,9 \%$. Porém, mais uma vez a taxa regional é elevada pela taxa do Distrito Federal $(19,7 \%)$, os estados possuem taxas menores, Mato Grosso do Sul (10,1\%), Mato
Grosso $(8,8 \%)$ e Goiás $(8,3 \%)$. Nesta faixa de anos de estudo estão compreendidos o ensino superior e o ensino técnico. Dentre as unidades federativas da região Centro-Oeste destaca-se o estado de Mato Grosso do Sul que, com o menor PIB da região CentroOeste, possui a segunda melhor taxa de pessoas com 25 anos ou mais com 15 anos de estudo.

Para a média nacional as taxas de $11 \mathrm{e}$ 15 anos de estudo, para o grupo populacional de 25 anos ou mais, é, respectivamente, de $21,5 \%$ e $9,5 \%$. Tanto no Brasil quanto na região Centro-Oeste a faixa de anos de estudos que mais compreende a população é a de 4 a 7 anos de estudo, $24,7 \%$ e $24,9 \%$ devidamente (IBGE, 2009).

Quando se analisa a renda das famílias, na região Centro-Oeste a renda média familiar da classe dos $10 \%$ mais pobres da população é de $\mathrm{R} \$ 105,7$, índice bem acima se comparado com outras regiões do país, Norte ( $\mathrm{R} \$ 66,96)$ e Nordeste $(\mathrm{R} \$ 44,31)$ e um pouco abaixo dos índices das regiões Sul (R\$ 126,41) e Sudeste (R\$ 119,41) (IBGE, 2009).

Analisando o rendimento médio da classe dos $40 \%$ mais pobres, vê-se uma grande diferença entre as regiões Norte e Nordeste e as demais regiões brasileiras, o que inclui a Centro-Oeste. O rendimento desta classe, na região Nordeste ( $\mathrm{R} \$ 112,83)$, é quase o mesmo que o rendimento das regiões Sul, Sudeste e Centro-Oeste para a classe dos $10 \%$ mais pobres. O rendimento para os $40 \%$ 
mais pobres na região Norte é de $\mathrm{R} \$ 145,32$, também bem abaixo do rendimento da população $40 \%$ mais pobre das regiões Sul ( $\mathrm{R} \$ 269,86)$, Sudeste ( $\$$ \$ 255,76) e CentroOeste (R\$220,59) (IBGE, 2009).

\section{O Gráfico 07 apresenta um} comparativo dos rendimentos da classe dos $40 \%$ mais pobres nas cinco regiões brasileiras.

Gráfico 07: Renda da população da classe dos $40 \%$ mais pobres por regiões brasileiras (em $\mathrm{R} \$)$.

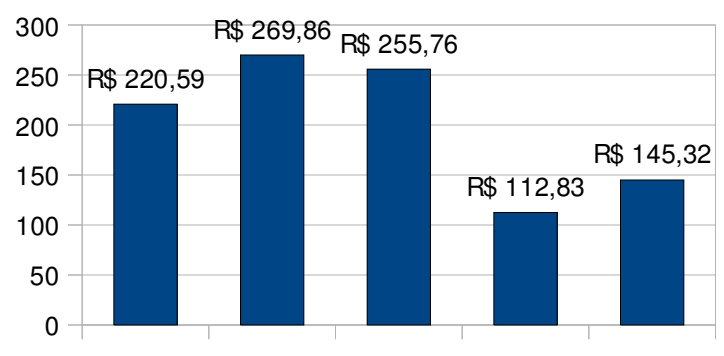

Reg. C-O Reg. Sul Reg. Sud. Reg. Nord Reg. Norte Fonte: Elaborado pelos autores com base em (IBGE, 2009).

A região Centro-Oeste tem o maior rendimento médio familiar da classe dos $10 \%$ mais ricos, $\mathrm{R} \$ 4.018,15$; porém este rendimento eleva-se por causa do rendimento do Distrito Federal, R \$ 7.411,14, muito acima do rendimento nacional, $\mathrm{R} \$ 3.160,36$. Para os estados da região Centro-Oeste os rendimentos são: Mato Grosso do Sul (R\$ 3.060,12), Mato Grosso (R $\$ 3.109,00)$ e Goiás (R\$ 2.923.31) (IBGE, 2009).

\subsection{Balança Comercial}

As exportações da região CentroOeste concentram-se, principalmente, em produtos não industrializados, agregando pouco valor à produção regional como mostra a Tabela 09, que apresenta dados por setor agregado.

Tabela 09: Exportações por setor agregado - Região

\begin{tabular}{l|cccc}
\multicolumn{4}{c}{ Centro-Oeste (jan-set.) e variação. } \\
\hline Descrição & $\begin{array}{c}\mathbf{2 0 0 9}(\mathbf{e m} \\
\text { US\$ bilhão) }\end{array}$ & $\begin{array}{c}\mathbf{2 0 1 0}(\mathbf{e m} \\
\text { US\$ bilhão) }\end{array}$ & $\begin{array}{c}\text { var. } \\
(\mathbf{\%})\end{array}$ \\
\hline Total & 11,151 & 12,134 & 8,8 \\
Básicos & 9,793 & 10,280 & 5,0 \\
Industrializ. & 1,359 & 1,854 & 36,4 \\
Semimanuf. & 1,042 & 1,429 & 37,1 \\
Manufatur. & 0,317 & 0,425 & 34,1
\end{tabular}

Fonte: Elaborado pelos autores com base em BANCO CENTRAL DO BRASIL (2010).

Verifica-se de acordo com os dados da Tabela 09 que no período de 2009 a 2010 houve uma elevação do valor das exportações da região Centro-Oeste, passando de US\$ 11,151 bilhões para US\$12,134 bilhões, uma variação de $8,8 \%$.

Porém percebe-se que a taxa de crescimento dos produtos industrializados, $36,4 \%$, tanto os semimanufaturados $(37,1 \%)$ quanto os manufaturados $(34,1 \%)$, são maiores que a taxa de crescimento da exportação de produtos básicos, 5,0\%.

No que se refere as importações por setor agregado, verifica-se, de acordo com a Tabela 10, que se destacam os bens de consumo e os bens intermediários. No caso dos bens de consumo, observa-se uma elevação de 55,7\% no período, passando de US\$ 1,529 bilhão em 2009 para US\$ 2,381 bilhões em 2010. 
Tabela 10: Importações por setor agregado - Região Centro-Oeste (jan-set.) e variação.

\begin{tabular}{l|ccc} 
Descrição & $\begin{array}{c}\mathbf{2 0 0 9}(\mathbf{e m} \\
\text { US\$ bilhão) }\end{array}$ & $\begin{array}{c}\mathbf{2 0 1 0}(\mathbf{e m} \\
\text { US\$ bilhão) }\end{array}$ & $\begin{array}{c}\text { var. } \\
\mathbf{( \% )}\end{array}$ \\
\hline Total & 5,437 & 7,380 & 35,7 \\
\hline Bens de cons. & 1,529 & 2,381 & 55,7 \\
Duráveis & 0,704 & 1,226 & 74,3 \\
Não duráveis & 0,826 & 1,155 & 39,9 \\
Bens intermed. & 1,754 & 2,731 & 55,7 \\
Bens de capital & 0,878 & 0,714 & $-18,6$ \\
Combustíveis e & 1,276 & 1,554 & 21,7 \\
lubrificantes & & & \\
\hline Fonte Elaborad
\end{tabular}

Fonte: Elaborado pelos autores com base em BANCO CENTRAL DO BRASIL (2010).

Com exceção dos bens de capital, que registraram queda de $18,6 \%$, todos os demais setores apresentaram taxas de crescimento da importação positivas, com destaque para a importação de bens duráveis, cujo aumento foi de $74,3 \%$ no período analisado. Considerando o total, as importações apresentaram alta de $35,7 \%$.

\section{CONSIDERAÇÕES FINAIS.}

A região Centro-Oeste possui IDH alto $(0,815)$ e o quarto PIB entre as regiões brasileiras. Os índices socioeconômicos da região, muitas vezes considerados bons, não representam a realidade regional, geralmente estes são elevados pela condição socioeconômica do Distrito Federal, subjugando a desigualdade socioeconômica entre as Unidades Federativas na região. Isto acontece, por exemplo, com a média do PIB per capita regional.

De forma geral, a região Centro-Oeste apresenta dados socioeconômicos bons, se comparados a média nacional. $\mathrm{O}$ IDH regional, analisando ao longo do tempo, sempre esteve acima da média do IDH nacional.

A análise da taxa de analfabetismo também, coloca a região Centro-Oeste a frente de regiões como Norte e Nordeste. O mesmo acontece com a análise da renda da população da classe dos $40 \%$ mais pobres.

Quanto a balança comercial do Centro-Oeste evidencia-se que a região agrega pouco valor à sua produção agropecuária e extrativista, levando a exportar, em sua maioria, produtos não industrializados. Por agregar pouco valor, a economia regional torna-se muito dependente dos preços das commodities.

Tanto os dados econômicos quanto os sociais economia mostram que na região Centro-Oeste ainda persistem problemas crônicos tais como: a baixa taxa de escolaridade, alta taxa de analfabetismo e analfabetismo informal, acesso aos básicos, e baixo valor agregado aos produtos exportados.

A região apresenta grandes potencialidades para seu desenvolvimento, se destaca quando numa comparação de seus índices sociais com outras regiões brasileiras, especificamente com as regiões Norte e Nordeste, porém ainda tem que superar seus entraves socioeconômicos.

\section{REFERÊNCIAS}

BANCO CENTRAL DO BRASIL. Boletim Regional. Brasília. 2010. Disponível em: http://www.bcb.gov.br/pec/boletimregional/port/201 0/10/br201010P.pdf. Acesso em: 08 dez. 2010. 
Humano e Trabalho Decente: a experiência brasileira recente. Brasília: Prima Página. 2008, p. 76-96.

FURTADO, Celso. Teoria e Política do Desenvolvimento Econômico. $2^{\circ}$ edição. São Paulo: Nova Cultural, 1986.

GUIMARÃES, Eduardo Nunes; LEME, Heládio José de Campos. Caracterização Histórica e Configuração Espacial da Estrutura Produtiva do Centro-Oeste. [Uberlândia], [1997]. Disponível em:http://www.nepo.unicamp.br/textos_publish/pron ex/pronexlivro03/03pronex_02_Caracterizacao_Hist orica.pdf. Acesso em: 01 out. 2009. 70 pgs.

IBGE. Contas Regionais do Brasil 2004-2008. Rio de Janeiro. 2010a. Disponível em: http://www.ibge.gov.br/home/estatistica/economia/c ontasregionais/2008/publicacao2008.pdf. Acesso em: 02 jan. 2011.

IBGE. Pesquisa de Orçamentos Familiares 20082009. Despesas, Rendimentos e Condições de Vida. Rio de Janeiro. 2010c.Disponível em: http://www.ibge.gov.br/home/estatistica/populacao/c ondicaodevida/pof/2008_2009/POFpublicacao.pdf. Acesso em: 3 fev. 2011.

IBGE. Síntese de Indicadores Sociais: uma análise das condições de vida da população brasileira. Rio de Janeiro. 2009. Disponível em: http://www.ibge.gov.br/home/estatistica/populacao/c ondicaodevida/indicadoresminimos/sinteseindicsoci ais2009/indic_sociais2009.pdf. Acesso em: 10 maio 2010.

MATO GROSSO DO SUL. Dados estatísticos de Mato Grosso do Sul. Campo Grande. 2009. Disponível em: http://www.semac.ms.gov.br/controle/ShowFile.php ?id=52984. Acesso em: 10 maio 2010.

MINISTÉRIO DA INTEGRAÇÃO NACIONAL. Plano Estratégico de Desenvolvimento do CentroOeste (2007-2020). [Brasília]. Disponível em: http://www.integracao.gov.br/desenvolvimentodocen trooeste/plano/index.asp. Acesso em: 08 dez. 2010.

PAVÃO, Eugênio da Silva. Formação, Estrutura e Dinâmica da Economia de Mato Grosso do Sul no Contexto das Transformações da Economia Brasileira. Dissertação, UFSC, 2005: Florianópolis. 250 pg. Disponível em: http://www.tede.ufsc.br/teses/PCNM0152.pdf.

Acesso em: 29 set. 2009.

SCHUMPETER, Joseph Alois. A Teoria do Desenvolvimento Econômico: uma investigação sobre lucros, capital, crédito, juro e o ciclo econômico. $2^{\circ}$ edição. São Paulo: Nova Cultural, 